\title{
Comparison of anticoagulants for the preservation of prothrombin time specimens
}

\author{
D. M. RAMSAY, E. P. ROBERTSON, AND E. MACARTHUR \\ From the Department of Haematology, Royal Infirmary, Lauriston Place, Edinburgh
}

SUMMARY The value of different anticoagulants as preservatives of specimens for prothrombin time ratios is evaluated and discussed. An increase in the ratio was demonstrated with all anticoagulants after 24 hours and this was significant when coagulometer error was taken into account. Both solid and liquid sodium citrate were superior to sodium oxalate as preservatives at 24 hours after taking off samples, but differences were slight and were not significant when coagulometer error was considered. It was concluded that for routine clinical practice, where a range of the prothrombin time ratio of $1 \cdot 8 / 1$ to $2 \cdot 5 / 1$ is allowable, there would be no significant advantage in any of the anticoagulants considered.

The use of oxalates as anticoagulants for the storage of venous blood samples is a recognised cause of progressive loss of factor $\mathrm{V}$ from these samples. In the initial phase, this loss of factor $V$ is counterbalanced by the activation of factor VII that oxalate produces, and the tendency towards a prolongation of values of the one-stage prothrombin time is probably compensated. Sodium citrate has been cited by Biggs and MacFarlane (1953) as the anticoagulant of choice for the prothrombin time as it is a better preservative of factor V. Neilson and Briggs (1957) have compared the use of citrate and oxalate in this respect and have shown that $3.8 \%$ sodium citrate solution is more reliable as a preservative at both 24 and 48 hours.

Until recently, commercial firms have produced disposable, dried mixed oxalate tubes (Wintrobe, 1951) and liquid citrate tubes for the collection of samples. The disadvantage of the latter was that they were subject to unsuspected leakage in distribution and in handling before use so that, not infrequently, blood specimens were found to be clotted on arrival at the laboratory. This was particularly unsatisfactory when the patient was seen as a hospital outpatient or by a general practitioner and when the anticoagulant therapy was controlled by postal means or by telephone which necessitated reattendance so that a repeat sample could be obtained. Oxalated blood did not present this problem but had the particular disadvantage that, when used in a van or postal service by general practitioners, a delay of up to 24 hours between taking and analysis of the

Received for publication 16 February 1977 sample might occur with significant loss of factor V. The artefactual lengthening of the prothrombin time thus engendered would result in underprescribing of the patient's anticoagulants and the possible danger of rethrombosis.

More recently, disposable solid citrate tubes have been available for trial purposes, and this paper evaluates and discusses the use of these against the traditional solid oxalate and liquid citrate tubes over the normal collection van service or postal transmission time for specimens in this area. The concentration of citrate, after addition of the recommended amount of blood, is higher with the solid citrate than with the liquid citrate tubes, but comparisons were made with these different concentrations since the tubes are available commercially in this way.

\section{Material and methods}

Containers for the collection and storage of specimens were disposable plastic tubes containing (1) $0.2 \mathrm{ml} 3.1 \%$ sodium citrate, $\mathrm{Na}_{3} \mathrm{C}_{6} \mathrm{H}_{5} \mathrm{O}_{7} .2 \mathrm{H}_{2} \mathrm{O}$ (MW 294), which had been evaporated to dryness at the bottom of the tube and calibrated to contain $2 \mathrm{ml}$ of whole blood (Staynes Laboratories Ltd); (2) $5 \mathrm{mg}$ dry mixture containing $3 \mathrm{mg}$ ammonium oxalate and $2 \mathrm{mg}$ potassium oxalate calibrated to contain $2.5 \mathrm{ml}$ whole blood (Staynes Labor itories Ltd); (3) $0.2 \mathrm{ml} 3.1 \%$ or 0.105 molar sodium citrate, $\mathrm{Na}_{3} \mathrm{C}_{6} \mathrm{H}_{5} \mathrm{O}_{7} .2 \mathrm{H}_{2} \mathrm{O}$ (MW 294), calibrated to receive $1.8 \mathrm{ml}$ whole blood (Teklab Laboratories Ltd).

Blood samples were obtained through 21 gauge needles by clean venepuncture into disposable 
plastic syringes and immediately transferred to the appropriate tube with gentle agitation to ensure rapid mixing of blood and anticoagulant without production of haemolysis. Specimens were centrifuged at $450 \mathrm{~g}$ for six minutes at room temperature and the one-stage prothrombin time was carried out on the plasma sample within two hours and after 24 hours' storage at room temperature and without further centrifugation. A Depex coagulometer was used for measuring the one-stage prothrombin time since automated methods give more reproducible results from person to person.

Test samples were obtained from patients on oral anticoagulant therapy, mainly oral warfarin, who were attending routine anticoagulant clinics. Normal controls were from members of hospital staff, none of whom was taking medications known to interfere with the test. The test and normal control samples were prepared and processed in an identical manner although no matching for age or sex was attempted. Before each run of test samples, three separate control plasmas were tested in duplicate, and the results were meaned. Duplicate prothrombin time values on each test plasma sample were then meaned and the ratio between the test and control plasmas was calculated to the nearest decimal place. This value is the prothrombin time ratio.

\section{Results}

Five trials were carried out; the first three compared oxalate and dried citrate as anticoagulants, the fourth liquid citrate and dried citrate, and the fifth compared all three anticoagulants. The results of the trials are given in Tables 1 and 2, which show, for each trial, the number of samples used in the tests of significance, the mean prothrombin time ratio and differences of ratios for the anticoagulants under comparison, the standard deviation and standard error of this difference, and the value of Student's $t$ test. Significant differences in mean values are denoted by asterisks in a standard fashion. Mean differences in prothrombin time ratios for the same anticoagulant, tested after 24 hours and within two hours, are shown in Table 1, and mean differences in ratios for different anticoagulants, tested after the same period of time, are shown in Table 2. The maximal effect of coagulometer error is also shown.

\section{Discussion}

The limitations of the Depex Coagulometer in recording to the actual second or above restricts the accuracy of the relatively short mean control time used in computing prothrombin time ratios. Comparisons made in this study may therefore be affected by two important factors-first, a difference between the preservatives which we wish to investigate and, secondly, differences between the two control times which constitute an important source of bias. To investigate the effect that this latter source might have on our comparisons, we considered the consequences of an error of 1 second in the total control times (ie, $\pm 1 / 6 \mathrm{~s}$ in the control means). The maximum effect that an error of this magnitude could have on our comparisons is shown in Tables 1 and 2.

The tests of significance employed have been the Student paired $t$ tests. It was felt that deviations from

Table 1 Comparison of prothrombin time ratios of samples tested in $<2$ hours and after 24 hours

\begin{tabular}{|c|c|c|c|c|c|c|c|c|}
\hline \multirow{2}{*}{$\begin{array}{l}\text { Difference } \\
\text { investigated }\end{array}$} & \multirow[t]{2}{*}{ Trial } & \multirow{2}{*}{$\begin{array}{l}\text { No. of } \\
\text { samples }\end{array}$} & \multicolumn{2}{|c|}{ Mean ratios } & \multirow{2}{*}{$\begin{array}{l}\text { Mean difference } \\
\pm \text { standard deviation }\end{array}$} & \multirow{2}{*}{$\begin{array}{l}\text { Standard error } \\
\text { of mean difference }\end{array}$} & \multirow{2}{*}{$\begin{array}{l}\text { Maximum } \\
\text { errort }\end{array}$} & \multirow{2}{*}{$\begin{array}{l}\text { Student } \\
\text { t test }\end{array}$} \\
\hline & & & '24' & ‘0’ & & & & \\
\hline $\mathrm{DC}_{24}-\mathrm{DC}$ & $\begin{array}{l}1 \\
2 \\
3 \\
4 \\
5\end{array}$ & $\begin{array}{l}36 \\
18 \\
20 \\
20 \\
19\end{array}$ & $\begin{array}{l}2 \cdot 511 \\
2 \cdot 522 \\
2 \cdot 195 \\
2 \cdot 215 \\
2 \cdot 305\end{array}$ & $\begin{array}{l}2 \cdot 206 \\
2 \cdot 372 \\
2 \cdot 030 \\
2 \cdot 190 \\
2 \cdot 321\end{array}$ & $\begin{array}{rc}0.305 & \pm 0.180 \\
0.150 & \pm 0.035 \\
0.165 & \pm 0.139 \\
0.025 & \pm 0.097 \\
-0.016 & \pm 0.096\end{array}$ & $\begin{array}{l}0.030 \\
0.035 \\
0.031 \\
0.022 \\
0.022\end{array}$ & $\begin{array}{l}0.0556 \\
0.0667 \\
0.0600 \\
0.0600 \\
0.0632\end{array}$ & $\begin{array}{l}10 \cdot 16 * * * \\
4 \cdot 31 * * * \\
5 \cdot 32 * * * \\
1 \cdot 16 \\
-0.72\end{array}$ \\
\hline$O X_{24}-O X_{0}$ & $\begin{array}{l}1 \\
2 \\
3 \\
5\end{array}$ & $\begin{array}{l}36 \\
18 \\
20 \\
19\end{array}$ & $\begin{array}{l}2 \cdot 483 \\
2 \cdot 617 \\
2 \cdot 265 \\
2 \cdot 479\end{array}$ & $\begin{array}{l}2 \cdot 225 \\
2 \cdot 400 \\
2 \cdot 105 \\
2 \cdot 384\end{array}$ & $\begin{array}{ll}0.258 & \pm 0.120 \\
0.217 & \pm 0.120 \\
0.160 & \pm 0.131 \\
0.095 & \pm 0.178\end{array}$ & $\begin{array}{l}0.020 \\
0.028 \\
0.029 \\
0.041\end{array}$ & $\begin{array}{l}0.0528 \\
0.0611 \\
0.0550 \\
0.0526\end{array}$ & $\begin{array}{l}12 \cdot 87^{* * *} \\
7 \cdot 66^{* * * *} \\
5 \cdot 45^{* * *} \\
2 \cdot 32 *\end{array}$ \\
\hline $\mathrm{LC}_{24}-\mathrm{LC}_{0}$ & $\begin{array}{l}4 \\
5\end{array}$ & $\begin{array}{l}20 \\
19\end{array}$ & $\begin{array}{l}2 \cdot 365 \\
2 \cdot 437\end{array}$ & $\begin{array}{l}2 \cdot 310 \\
2 \cdot 426\end{array}$ & $\begin{array}{l}0.055 \pm 0.119 \\
0.011 \quad \pm 0.074\end{array}$ & $\begin{array}{l}0.027 \\
0.017\end{array}$ & $\begin{array}{l}0.0526 \\
0.0632\end{array}$ & $\begin{array}{l}2 \cdot 07 \\
0 \cdot 62\end{array}$ \\
\hline
\end{tabular}

DC, ratios using dried citrate as anticoagulant (DC - -tested in $<2$ hours; DC - $_{24}$ tested after 24 hours); OX, ratios using oxalate as anticoagulant (OX $\mathrm{X}_{\mathbf{0}}$-tested in $<2$ hours; $\mathrm{OX}_{\mathbf{2 4}}$-tested after 24 hours); LC, ratios using liquid citrate as anticoagulant (LC - tested in $<2$ hours, $\mathrm{LC}_{\mathbf{2 4}}$-tested after 24 hours)

$\uparrow$ Maximum error in mean difference allowing for $1 / 6$ second error in mean control times

* Significant at the $5 \%$ level

* * Significant at the $2 \%$ level

*** Significant at the $0.5 \%$ level 
Table 2 Comparison of prothrombin time ratios of samples in different anticoagulants

\begin{tabular}{|c|c|c|c|c|c|c|}
\hline $\begin{array}{l}\text { Difference } \\
\text { investigated }\end{array}$ & Trial & $\begin{array}{l}\text { No. of } \\
\text { samples }\end{array}$ & $\begin{array}{l}\text { Mean difference } \\
\pm \text { standard deviation }\end{array}$ & $\begin{array}{l}\text { Standard error } \\
\text { of mean difference }\end{array}$ & $\begin{array}{l}\text { Maximum } \\
\text { errort }\end{array}$ & $\begin{array}{l}\text { Student } \\
\text { t test }\end{array}$ \\
\hline $\mathrm{DC}_{\mathbf{0}}-\mathrm{OX}$ & $\begin{array}{l}1 \\
2 \\
3 \\
5\end{array}$ & $\begin{array}{l}36 \\
18 \\
20 \\
19\end{array}$ & $\begin{array}{ll}-0.019 & \pm 0.119 \\
-0.028 & \pm 0.153 \\
-0.075 & \pm 0.121 \\
-0.063 & \pm 0.116\end{array}$ & $\begin{array}{l}0.020 \\
0.036 \\
0.027 \\
0.027\end{array}$ & $\begin{array}{l}0.0500 \\
0.0389 \\
0.0600 \\
0.0632\end{array}$ & $\begin{array}{l}-0.980 \\
-0.77 \\
-2 \cdot 77^{*} \\
-2 \cdot 36^{*}\end{array}$ \\
\hline $\mathrm{DC}_{24}-\mathrm{OX}_{24}$ & $\begin{array}{l}1 \\
2 \\
3 \\
5\end{array}$ & $\begin{array}{l}36 \\
18 \\
20 \\
19\end{array}$ & $\begin{array}{rc}0.028 & \pm 0.168 \\
-0.094 & \pm 0.195 \\
-0.070 & \pm 0.092 \\
-0.174 & \pm 0.205\end{array}$ & $\begin{array}{l}0.028 \\
0.028 \\
0.021 \\
0.097\end{array}$ & $\begin{array}{l}0.0556 \\
0.0556 \\
0.0550 \\
0.0789\end{array}$ & $\begin{array}{l}0.990 \\
-2.05 \\
-3.39 * * \\
-3.69 * *\end{array}$ \\
\hline $\mathrm{LC}_{0}-\mathrm{DC}_{\mathrm{o}}$ & $\begin{array}{l}4 \\
5\end{array}$ & $\begin{array}{l}20 \\
19\end{array}$ & $\begin{array}{l}0.120 \pm 0.106 \\
0.105 \pm 0.103\end{array}$ & $\begin{array}{l}0.024 \\
0.024\end{array}$ & $\begin{array}{l}0.0789 \\
0.0632\end{array}$ & $\begin{array}{l}5 \cdot 08 * * * \\
4 \cdot 47 * * *\end{array}$ \\
\hline $\mathrm{LC}_{24}-\mathrm{DC}_{24}$ & $\begin{array}{l}4 \\
5\end{array}$ & $\begin{array}{l}20 \\
19\end{array}$ & $\begin{array}{l}0.150 \pm 0.110 \\
0.132 \quad \pm 0.106\end{array}$ & $\begin{array}{l}0.025 \\
0.024\end{array}$ & $\begin{array}{l}0.0650 \\
0.0526\end{array}$ & $\begin{array}{l}6 \cdot 10 * * * \\
5 \cdot 43 * * *\end{array}$ \\
\hline $\mathrm{LC}_{0}-\mathrm{OX} \mathrm{X}_{\mathrm{o}}$ & 5 & 19 & $0.042 \pm 0.084$ & 0.019 & 0.0789 & $2 \cdot 19^{*}$ \\
\hline $\mathrm{LC}_{24}-\mathrm{OX}_{24}$ & 5 & 19 & $-0.042 \pm 0.222$ & 0.051 & 0.0842 & -0.83 \\
\hline
\end{tabular}

$\dagger$ Maximum error in mean difference allowing for $1 / 6$ second error in mean control times

* Significant at the $5 \%$ level

**Significant at the $2 \%$ level

***Significant at the $0.5 \%$ level

normality of these paired differences would not greatly affect the results owing to the robustness of the $t$ test. From the preceding discussion it is clear that some of the statistically significant differences reported could be due to coagulometer error affecting the respective control times.

There was an increase in the prothrombin time ratio after 24 hours for all anticoagulants though the increase was not statistically significant in the case of liquid citrate. Dried citrate in trials 1,2 , and 3 , and oxalate in all trials, gave a significant increase in the value of the ratio, and this was maintained when the error of the coagulometer was taken into account. The increase of ratio after 24 hours, using oxalate, was comparable to that induced by citrate as anticoagulant in the first three trials.

Oxalate gave a significantly greater prothrombin time ratio than dried citrate both immediately and after 24 hours in most trials comparing the two anticoagulants. The increase was more pronounced at 24 hours except in trial 1 where the mean ratio using oxalate was inexplicably lower. Apart from this anomaly, citrate appeared to be a slightly better anticoagulant than oxalate for the preservation of the test samples. The significance of the figures for the two anticoagulants was, however, lost in all trials apart from the last, when the error of the coagulometer was again considered. It should be noted that these conclusions do not necessarily hold for results where the prothrombin activity or prothrombin index are reported.

The significantly increased prothrombin time ratio of liquid citrate as compared with solid citrate within two hours and at 24 hours probably reflects the dilution factor of the former anticoagulant on the whole blood sample. Comparison of liquid citrate with oxalate also shows the effect of dilution on samples tested immediately in that prothrombin time ratios with liquid citrate were greater in value though not significantly so. After 24 hours the slightly superior preservation of the sample by citrate as anticoagulant reverses this trend so that the mean prothrombin time ratio is less, but again not significantly so. This hypothesis could be tested by comparing the prothrombin time ratios of liquid citrate plasma, solid citrate plasma, and solid citrate plasma to which a volume of water has been added equal to that of the citrate solution with which the blood has been mixed. It was decided that this was outside the scope of the trials which were to compare anticoagulant tubes as supplied by the manufacturers.

In evaluating the different anticoagulants for routine clinical use, other factors besides the preservation of a true prothrombin time ratio must be considered. One specimen clotted in trials 2 and 5 , the anticoagulants being dried citrate and oxalate mixture respectively. This represented sample clotting under ideal conditions of collection and mixing. Under normal conditions of usage in the department, oxalate mixture, which is routinely used for prothrombin times, and liquid citrate, which is routinely used for thrombin times, are rarely associated with clotted specimens being received. Solid citrate, on the other hand, is a difficult anticoagulant to mix with blood, and a considerable proportion of samples in this anticoagulant, taken by a clinic house officer and sent to the laboratory on a previous occasion, were found to be clotted. Determination of activation of clotting, 
in parallel specimens taken into liquid and solid citrate tubes, by assaying factor VII would have been of value in this respect but was not carried out in the trials undertaken. Spray-filling of the solid citrate tubes, instead of evaporating the anticoagulant to dryness at the bottom of the tube, might also help to overcome the problem of clotted samples.

When these factors are considered together with the marginal preservative value of citrate as an anticoagulant and with the biological variation of patient response to anticoagulant therapy and the wide range of 'normal' levels of anticoagulation (ie, prothrombin time ratio $1 \cdot 8 / 1$ to $2 \cdot 5 / 1$ in this laboratory), there is no significant advantage in any of the anticoagulants as long as specimens are received within the 24-hour period.

References

Biggs, R., and MacFarlane, R. G. (1953). Human Blood Coagulation and its Disorders, p. 153. Blackwell, Oxford.

Neilson, D. B., and Briggs, E. M. G. (1957). The effect of delay on the estimation of the 'prothrombin time'. Scottish Medical Journal, 2, 284-287.

Wintrobe, M. W. (1951). Clinical Hematology, 3rd edition, p. 302. Henry Kimpton, London. 